\title{
Reduced tonic inhibition in striatal output neurons from Huntington mice due to loss of astrocytic GABA release through GAT-3
}

\author{
Anna M. Wójtowicz ${ }^{1,2+}$, Anton Dvorzhak ${ }^{1,2+}{ }^{+}$, Marcus Semtner $^{3}$ and Rosemarie Grantyn ${ }^{1,2 *}$ \\ ${ }^{1}$ Cluster of Excellence NeuroCure, University Medicine Charité, Berlin, Germany \\ ${ }^{2}$ Department of Experimental Neurology, University Medicine Charité, Berlin, Germany \\ ${ }^{3}$ RNA Editing and Hyperexcitability Disorders Group, Department of Neuroscience, Max Delbrück Center for Molecular Medicine, Berlin, Germany
}

\section{Edited by:}

Alexey Semyanov, RIKEN Brain

Science Institute, Japan

Reviewed by:

Yoland Smith, Emory University, USA

Astrid Linthorst, University of Bristol, UK

\section{*Correspondence:}

Rosemarie Grantyn, Cluster of Excellence Neurocure and

Department of Experimental

Neurology, University Medicine

Charitè, Robert-Koch-Platz 4,

D-10115 Berlin, Germany

e-mail: rosemarie.grantyn@

charite.de

${ }^{t}$ These authors have contributed equally to this work.
The extracellular concentration of the two main neurotransmitters glutamate and GABA is low but not negligible which enables a number of tonic actions. The effects of ambient GABA vary in a region-, cell-type, and age-dependent manner and can serve as indicators of disease-related alterations. Here we explored the tonic inhibitory actions of GABA in Huntington's disease (HD). HD is a devastating neurodegenerative disorder caused by a mutation in the huntingtin gene. Whole cell patch clamp recordings from striatal output neurons (SONs) in slices from adult wild type mice and two mouse models of HD (Z_Q175_KI homozygotes or R6/2 heterozygotes) revealed an HD-related reduction of the GABA(A) receptor-mediated tonic chloride current ( I Tonic(GABA) $\left._{\text {) }}\right)$ along with signs of reduced $G A B A(B)$ receptor-mediated presynaptic depression of synaptic GABA release. About half of $\mathrm{I}_{\text {Tonic(GABA) }}$ depended on tetrodotoxin-sensitive synaptic GABA release, but the remaining current was still lower in HD. Both in WT and HD, ITonic(GABA) was more prominent during the first $4 \mathrm{~h}$ after preparing the slices, when astrocytes but not neurons exhibited a transient depolarization. All further tests were performed within $1-4 \mathrm{~h}$ in vitro. Experiments with SNAP5114, a blocker of the astrocytic GABA transporter GAT-3, suggest that in WT but not HD GAT-3 operated in the releasing mode. Application of a transportable substrate for glutamate transporters (D-aspartate 0.1-1 mM) restored the non-synaptic

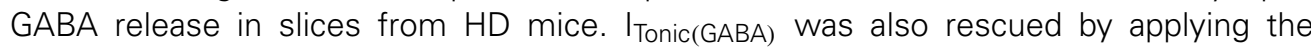
hyperagonist gaboxadol $(0.33 \mu \mathrm{M})$. The results lead to the hypothesis that lesion-induced astrocyte depolarization facilitates non-synaptic release of GABA through GAT-3. However, the capacity of depolarized astrocytes to provide GABA for tonic inhibition is strongly reduced in HD.

Keywords: GABAergic synaptic transmission, astrocyte, GAT-3, ambient GABA, GABA(A) receptor, GABA(B) receptor, presynaptic depression, Huntington's disease

\section{INTRODUCTION}

In contrast to the low-affinity $\mathrm{GABA}(\mathrm{A})$ receptors in the postsynaptic density, extrasynaptic GABA(A) receptors populating the somato-dendritic membrane of mature neurons display sufficient sensitivity to report the presence of GABA at submicromolar concentrations (Semyanov et al., 2004; Farrant and Nusser, 2005; Glykys and Mody, 2007a; Brickley and Mody, 2012). In addition, low concentrations of GABA in the environment of synaptic terminals are detected by presynaptic GABA(B) receptors (Le Feuvre et al., 1997; Kirmse and Kirischuk, 2006; Mapelli et al., 2009; Dvorzhak et al., 2010; Laviv et al., 2010). Both signaling pathways may interact for homeostatic adjustment of synaptic vs. non-synaptic GABAergic input (Mody, 2005; Connelly et al., 2013).

Tonic GABA actions vary strongly in a region-as well as celltype-specific manner (Semyanov et al., 2003; Song et al., 2011). In the rodent striatum, where GABA-synthesizing cells constitute the vast majority of the neuron population, tonic chloride currents via extrasynaptic GABA(A) receptors (termed $\mathrm{I}_{\text {Tonic(GABA) }}$ ) were consistently recorded as depolarizing shifts in the baseline currents in response to GABA(A) receptor block (Ade et al., 2008; Janssen et al., 2009; Santhakumar et al., 2010; Cepeda et al., 2013). Changes in vesicular transmitter release after bath-application of a specific $\mathrm{GABA}(\mathrm{B})$ receptor-blocker present evidence for tonic presynaptic GABA effects, at least under condition of reduced GABA uptake (Kirmse et al., 2009). The indicators of tonic extrasynaptic and presynaptic GABA actions can mutually validate each other, although the presynaptic depression is probably less sensitive (Kirmse et al., 2008).

It is obvious that the strength of tonic inhibition will not only depend on the characteristics of the respective receptors (Scimemi et al., 2005; Ransom et al., 2010) and the amount of "spillover" after vesicular GABA release (Glykys and Mody, 2007b) but also on the distribution and transport of GABA from and into the extracellular space (Wu et al., 2007; Ransom et al., 2013). In the present study, the focus will be placed on the role of the astrocytic GABA transporter GAT-3 as a potential source of non-synaptic GABA release (Yoon et al., 2012). 
A comprehensive description of the structure, cellular distribution and function of GABA transporters (GATs) can be found in (Borden, 1996; Dalby, 2003; Richerson and Wu, 2003; Jin et al., 2011a). Four different GATs are known, with somewhat confusing nomenclature in mice $v s$. rat. The expression of GAT- 1 and GAT-3 is brain-specific, where GAT-1 protein is preferentially localized in neurons, notably in their presynaptic terminals (Radian et al., 1990), and GAT-3 is preferentially localized on the processes of astrocytes (Minelli et al., 1996; Ribak et al., 1996).

As other neurotransmitter transporters, GABA transporters can reverse their transport direction (Wu et al., 2007). However, the conditions necessary for reversal may vary in dependence of the given stoichiometry. While a glutamate uptake cycle through the major astrocytic transporter GLT-1 (EAAT-2) is associated with an inward move of three $\mathrm{Na}^{+}$and one proton and an outward move of one $\mathrm{K}^{+}$, a GABA uptake cycle through GAT-3 only co-transports two $\mathrm{Na}^{+}$and one $\mathrm{Cl}^{-}$. Thus, the driving forces at resting membrane potentials are much lower for the GABA transport. Reversal may therefore easily occur under a variety of physiological as well as pathophysiological conditions.

In general, one can expect that excessive excitation leading to membrane depolarization, loss of potassium, and elevation of intracellular sodium levels will increase the likelihood that sites of GABA uptake are converted into sites of non-synaptic GABA release (Richerson and $\mathrm{Wu}, 2003$ ). At the same time, glutamate transporters might continue to operate in the uptake mode. Thus, within a range of cellular perturbations, opponent glutamate and GABA transport may form a basis of neuroprotection, as recently suggested by Heja et al. (2012). These authors presented evidence that high activity of astrocytic glutamate uptake facilitates non-synaptic GABA release through GAT-3. Their hypothesis also predicts that, due to co-localization of GLT-1 and GAT-3, a failure in astrocytic glutamate uptake would affect the neuronal response to non-synaptic GABA release from astrocytes.

A devastating neurological condition associated with insufficiency of astrocytic glutamate uptake is Huntington's disease (HD). HD belongs to the group of inherited polyglutamine disorders that derive from a CAG triplet repeat expansion. The pathologically expanded tract of glutamines is toxic and causes neurodegeneration, especially in the striatum. At earlier stages of the disease, the afflicted individuals suffer from emotional and cognitive disturbances, but also from uncoordinated movements. This state (Ross and Tabrizi, 2011; Ha and Fung, 2012) is also known as chorea. Striatal neurons expressing a mutant form of huntingtin are characterized by hyperexcitability (Dvorzhak et al., 2013) and pathological spontaneous action potential generation (Miller et al., 2011). Several studies have suggested that in the HD striatum reduced glutamate uptake through GLT-1 may impair the capacity of astrocytes to support normal levels of neuronal activity (Lievens et al., 2001; Behrens et al., 2002; Miller et al., 2008; Faideau et al., 2010; Petr et al., 2013), but it is not yet known as to what extent tonic GABA effects, in general, and GAT-3 function, in particular, were altered in symptomatic HD.

In the present study, we have used two different mouse models of $\mathrm{HD}$ to quantify the possible changes in tonic extrasynaptic and presynaptic GABA actions. The results presented here will lead to the conclusion that $\mathrm{I}_{\mathrm{Tonic}}(\mathrm{GABA})$ and tonic $\mathrm{GABA}(\mathrm{B})$ receptor-mediated depression of synaptic GABA release are less potent in $\mathrm{HD}$ because the $\mathrm{HD}$-afflicted astrocytes have a reduced capacity to release GABA via GAT-3.

\section{MATERIALS AND METHODS ETHICAL APPROVAL}

The present experiments were performed in fully adult (315-450 days) wild-type mice from a colony of Z-Q175-KI provided by the CHDI ("Cure Huntington's Disease Initiative") foundation and R6/2 mice provided by Charles River GmbH Germany. Every precaution was taken to minimize stress and to reduce the number of animals used in each series of experiments. The work described here has been carried out in accordance with the EU Directive 2010/63/EU for animal experiments and complies with the requirements for manuscripts submitted to biomedical journals. The work was registered at the Office of Health Protection and Technical Safety of the regional government Berlin (Landesamt für Arbeitsschutz, Gesundheitsschutz und Technische Sicherheit Berlin, T0448/12).

\section{TRANSGENIC MICE}

The Z-Q175-KI mouse line was created by Cerebricon Ltd/Charles River Labs, Kuopio, Finland and CHDI Fndn. Inc., Princeton, NJ, and provided by the Jackson Labs, Bar Harbor, USA (ME \#370437). It originated from the Q140 knock-in (KI) mouse described by Menalled et al. (2003) and express a chimeric mouse/human exon 1 mhtt. The R6/2 mouse line (B6CBA-Tg(HDexon1)62Gpb/3J, Jackson Labs, Bar Harbor, ME \#006494) was derived from the transgenic mouse line generated by Mangiarini et al. (1996). The mice were genotyped by PCR and analyzed for CAG length. Experiments were either performed in Q175 homozygotes or in R6/2 heterozygotes and their respective wild-type siblings. We shall refer to the normal wild-type mice as "WT" and to mice carrying a mutant form of huntingtin as "HD mice" or just "HD." For more information on the mice see Dvorzhak et al. (2013). Briefly, average CAG length was $120 \pm 0.2$ (range $=114-127, n=137$ ) in $\mathrm{R} 6 / 2$ and $184.6 \pm 0.7$ (range $=172-195, n=68)$ in Q175. The average age was $78.0 \pm 1.1 \mathrm{~d}, n=91$ vs. HD $75.0 \pm 1.2 \mathrm{~d}, n=77$ (n.s.) in R6/2 and $400.3 \pm 2.6 \mathrm{~d}, n=54$ vs. $405.6 \pm 4.9 \mathrm{~d}, n=68$ (n.s.) in Q175. All of the Q175 mice were older than 1 year. Considering the absence of sex- and age-dependent differences in the tested parameters we have accordingly pooled the data from the WT and HD cohorts.

\section{SLICE PREPARATION}

The animals were deeply anesthetized by inhalation of a mixture of isoflurane and carbogen $\left(95 \% \mathrm{O}_{2}\right.$ and $\left.5 \% \mathrm{CO}_{2}\right)$ and transcardially perfused with $60 \mathrm{ml}$ of ice-cold $\left(\sim 4^{\circ} \mathrm{C}\right)$ saline containing (in $\mathrm{mM}$ ): 125 choline chloride, $2 \mathrm{KCl}, 1.25 \mathrm{NaH}_{2} \mathrm{PO}_{4}$, $25 \mathrm{NaHCO}_{3}, 0.5 \mathrm{CaCl}_{2}, 7 \mathrm{MgCl}_{2}, 10$ glucose, $0.5 \mathrm{CaCl}_{2}, 7 \mathrm{MgCl}_{2}$ ( $\mathrm{pH} 7.25,305$ mosmol/l). The 1 year and older Q175 mice were initially prepared in the same solution, but in a second series of experiments (Figures 4, 5) the Q175 mice were transcardially perfused with ice-cold saline before removing the brains from the skull. The choline-based perfusion solution was supplemented with $5 \mu \mathrm{M}$ glutathione, $500 \mu \mathrm{M}$ Na pyruvate, $2.8 \mathrm{mM}$ ascorbic 
acid, and $1 \mu \mathrm{M}$ of $\mathrm{MK}-801$. The brain was removed quickly $(\sim 1 \mathrm{~min})$, separated into two hemispheres and transferred into ice-cold oxygenated saline. Sagittal slices of $300 \mu \mathrm{m}$ were prepared with a vibrating microtome (Integraslice 7550PSDS, Campden Instruments Ltd., Loughborough, UK) and then maintained for at least $1 \mathrm{~h}$ in artificial cerebrospinal fluid (ACSF) that contained (in $\mathrm{mM}$ ): $125 \mathrm{NaCl}, 2 \mathrm{KCl}, 1.25 \mathrm{NaH}_{2} \mathrm{PO}_{4}, 25 \mathrm{NaHCO}_{3}, 2 \mathrm{CaCl}_{2}$, $1 \mathrm{MgCl}_{2}, 10$ glucose, 0.5 pyruvic acid, 0.005 glutathione, and 2.8 ascorbic acid(pH 7.35, $303 \mathrm{mosmol} / \mathrm{l})$.

\section{SOLUTIONS AND CHEMICALS}

During experiments, $10 \mu \mathrm{M}$ DNQX and $50 \mu \mathrm{M}$ DL-2-amino5-phosphonopentanoic acid (APV) were added to the ACSF to block glutamatergic currents. The remaining postsynaptic currents were completely blocked by bicuculline methiodide (BMI, $25 \mu \mathrm{M}$ ) or SR-95531 (gabazine, $10 \mu \mathrm{M}$ ), but not by strychnine $(30 \mu \mathrm{M})$, indicating their GABAergic nature. The following pharmacological agents were obtained from Tocris (Bristol, UK) and applied at indicated concentrations: gaboxadol or 4,5,6,7tetrahydroisoxazolo[5,4-c]pyridin-3-ol hydrochloride (THIP, 0.1-1 $\mu \mathrm{M}), \quad$ (2S)-3-(1S)-1-(3,4-dichlorophenyl)ethyl]amino2-hydroxypropyl](phenylmethyl)phosphinic acid (CGP55845, CGP, $1 \mu \mathrm{M})$, LY341495 $(40 \mu \mathrm{M}$ and $0.1 \mu \mathrm{M}), 1-[2-[\operatorname{tris}(4-$ methoxyphenyl)methoxy] ethyl]-(S)-3-piperidinecarboxylic acid ((S)-SNAP5114, $40 \mu \mathrm{M})$. Tetrodotoxin (TTX, $1 \mu \mathrm{M}$ ) was obtained from Alomone Labs (Jerusalem, Israel). All other chemicals were from Sigma-Aldrich (Munich, Germany), including 1-[2-[[(diphenylmethylene)imino] oxy] ethyl]-1,2,5,6tetrahydro-3-pyridinecarboxylic acid hydrochloride (NO-711, $10 \mu \mathrm{M}), \mathrm{D}$-aspartic acid monosodium salt (D-Asp, 0.1-1 mM). Other concentrations are given in the Results section.

\section{PATCH CLAMP RECORDING}

For electrophysiological tests, slices were submerged into a perfusion chamber with a constant flow of oxygenated ACSF. The flow rate was set to $1-2 \mathrm{ml} \mathrm{min}^{-1}$. Temperature during the recordings was maintained at $26-27^{\circ} \mathrm{C}$. Preceding experiments at various maintenance temperature (range $=23-30^{\circ} \mathrm{C}$ ) showed that under the given conditions slices from animals $>1$ year were best maintained at this temperature, the quality criterion being the level of neuronal membrane potentials at break-in, in addition to the appearance of the slices. In HD mice, one could see debris from degenerating axons in the globus pallidus and substantia nigra suggesting some degree of neurodegeneration.

Pipette resistance was 3-6 MOhm when filled with the following saline (in $\mathrm{mM}$ ): $150 \mathrm{KCl}, 5 \mathrm{NaCl}, 0.5 \mathrm{CaCl}_{2}, 5 \mathrm{EGTA}$, 25 HEPES, 2 MgATP, 0.3 GTP (for recording tonic chloride currents) and 100 potassium gluconate, $50 \mathrm{KCl}, 5 \mathrm{NaCl}, 0.5 \mathrm{CaCl}_{2}$, 5 EGTA, 25 HEPES, 2 MgATP, 0.3 GTP (for recording IPSCs). The calculated equilibrium potentials for chloride $\left[\mathrm{E}_{\mathrm{Cl}^{-}}\right]$were 4 and $-21 \mathrm{mV}$, respectively.

Electrophysiological signals were acquired using an EPC-8 amplifier (List, Darmstadt, Germany), a 16-bit AD/DA board (ITC-16, HEKA Elektronik, Lambrecht, Germany) and the software TIDA 4.11 (HEKA Elektronik, Lambrecht, Germany). The signals were sampled at a rate of $10 \mathrm{kHz}$ and filtered at $3 \mathrm{kHz}$. Liquid junction potentials were not corrected. In neurons, the holding potential was set to $-70 \mathrm{mV}$ which was close to the resting membrane potential recorded in these cells in the current clamp mode immediately after break-in. Access resistance was monitored by applying pulses of $-10 \mathrm{mV}$. Cell capacitance and access resistance values were obtained by fitting a monoexponential function to the capacitance transients. Only recordings with a series resistance below $30 \mathrm{MOhm}$ were accepted (in typical cases series resistance amounted to 15-20 MOhm). Series resistance compensation was not applied. Cells exhibiting more than a $20 \%$ change in the access resistance during an experiment were discarded. Resting membrane potentials of neurons and suphorhodamine-labeled astrocytes were measured immediately after break-in.

\section{IDENTIFICATION OF ASTROCYTES}

Protoplasmic astrocytes were identified by staining with sulforhodamine 101 (SR101) (Nimmerjahn et al., 2004). The original protocol was modified to optimize the labeling in slices from adult and, in case of HD, rather sick mice. Briefly, $30 \mathrm{~min}$ after preparation slices were transferred into oxygenized ACSF containing $6 \mu \mathrm{M} \mathrm{SR} 101$ and maintained at $37^{\circ} \mathrm{C}$ for $10 \mathrm{~min}$. After this the slices were washed and stored for at least $40 \mathrm{~min}$ in standard ACSF at room temperature. Astrocyte staining was visualized under fluorescence optics using an excitation wavelength of $573 \mathrm{~nm}$ controlled by a monochromator system (polychrome V) from Till Photonics (Gräfelfing, Germany). The dichroic mirror (QMAX/DI580LP) and emission filter (QMAX/EM600-650) were from Omega Optical, Brattleboro, VT, USA.

\section{ELECTRICAL STIMULATION AND RECORDING OF UNITARY EPSCS}

Unitary evoked excitatory postsynaptic currents (eEPSCs) were elicited by intrastriatal microstimulation via a glass pipette filled with ACSF as described before (Dvorzhak et al., 2013). Briefly, glass pipettes filled with ACSF had a resistance of about $10 \mathrm{MOhm}$ and were moved in the dorsal striatum in the vicinity of the recorded neuron until the recording pipette detected a postsynaptic response. Sometimes neurons were filled with Lucifer Yellow which helped to avoid positions that could lead to direct depolarization of dendrites. An isolated stimulation unit was used to generate rectangular electrical pulses. Pulse duration was set at $0.5 \mathrm{~ms}$. Pulse intensity was adjusted to activate a synaptic response at minimal intensity and with distinct threshold. Stimulation was accepted as unitary if the following criteria were satisfied: (1) eIPSC latency remained stable ( $<20 \%$ fluctuations), (2) lowering stimulus intensity by $20 \%$ resulted in a complete failure of eIPSCs, (3) an increase in stimulus intensity by $20 \%$ neither changed mean eIPSC amplitude nor eIPSC shape, (4) there was no contamination by glutamatergic synaptic input. Typical current intensities required for unitary stimulation ranged between 0.4 and $0.6 \mu \mathrm{A}$. Paired pulses were delivered at an inter-stimulusinterval of $50 \mathrm{~ms}$ at a repetition frequency of $0.1-0.2 \mathrm{~Hz}$ to allow for full recovery of transmitter release after paired pulse stimulation at an interval of $50 \mathrm{~ms}$.

Although there is no proof that only 1 axon had been stimulated in any given case, we regard it as highly probable that the responses induced by minimal stimulation were indeed "unitary eIPSCs," i.e., responses to activation of just one presynaptic 
neuron. For the sake of simplicity, evoked IPSCs will in the following be referred to as eIPSCs, assuming that in the vast majority of cases we have dealt with unitary connections.

\section{DATA EVALUATION AND STATISTICS}

All data was evaluated off-line using TIDA 4.11 (HEKA Elektronik, Lambrecht, Germany), IgorPro6.0 (WaveMetrics, Lake Oswego, OR, USA), Prism 6.01 (Graphpad, San Diego, CA, USA), SPSS 21 (SPSS GmbH Software, Munich, Germany). $\mathrm{I}_{\text {Tonic(GABA) was defined as the difference of baseline currents }}$ in the absence and presence of BMI $(20 \mu \mathrm{M})$. The size of $\mathrm{I}_{\text {Tonic(GABA) }}$ was verified by plotting all-points histograms for $30 \mathrm{~s}$ periods immediately before and during BMI application using a custom-written macro in IgorPro6.0 (WaveMetrics, Lake Oswego, OR, USA). Gaussian functions were fitted to the part of the distribution not skewed by synaptic events, and $\mathrm{I}_{\text {Tonic(GABA) }}$ was determined as the distance between the two amplitude peaks.

The quantitative results are presented as mean \pm s.e.m. The error bars in the figures indicate s.e.m. Data points and means from $\mathrm{HD}$ mice are presented with gray fill. The numbers in brackets are the number of tested neurons. Normality of data distributions was evaluated by the Kolmogorov-Smirnov or the Shapiro-Wilk test. Differences between means were determined by paired or unpaired $t$-test (normally distributed data) and Wilcoxon matched-pairs signed rank test or Mann-Whitney test (not normally distributed data). Bonferroni correction was implemented in case of multiple comparison tests. One-Way ANOVA (normally distributed data) or Kruskal-Wallis statistics (not normally distributed data) was used for differences between 3 groups of data from different cells. Two-Way ANOVA with post-hoc Bonferroni correction was performed for experiments in the classical $2 \times 2$ design, with 2 independent factors (genotype and treatment). Fitting of regression curves to data points was performed on the basis of the Spearman test. The asterisks in the figures indicate the following: ${ }^{*} p<0.05,{ }^{* *} p<0.01$, and ${ }^{* * *} p<0.001$.

\section{RESULTS}

THE GABA(A) RECEPTOR-MEDIATED TONIC CHLORIDE CURRENT AND THE GABA(B) RECEPTOR-MEDIATED DEPRESSION OF SYNAPTIC GABA RELEASE AS REPORTERS OF AMBIENT GABA CONCENTRATION IN THE MURINE STRIATUM

Extrasynaptic GABA(A) receptors and presynaptic GABA(B) receptors display high affinities for $\mathrm{GABA}$, the respective $\mathrm{EC}_{50}$ values in slice preparations being $0.1-0.25 \mu \mathrm{M}$ (Dvorzhak et al., 2010) and 1.5-5 $\mathrm{MM}$ (Le Feuvre et al., 1997). They are therefore well-suited to indicate the presence of extracellular GABA concentrations $\left([\mathrm{GABA}]_{\mathrm{ec}}\right)$ in the lower micromolar range. Moreover, the combined use of the two indicators helps to mutually validate the obtained results. Figure 1 illustrates this experimental approach when applied to WT and HD SONs.
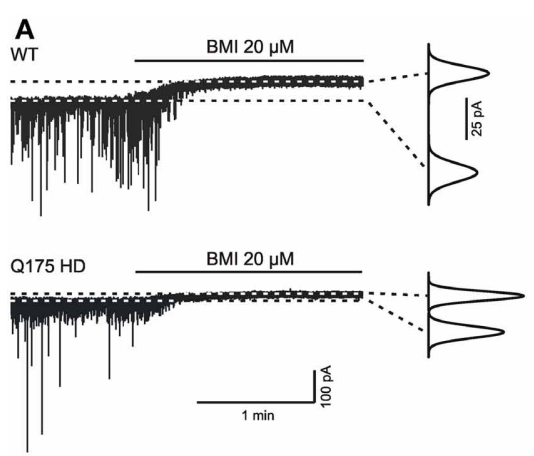

B

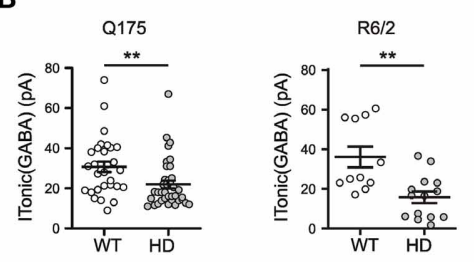

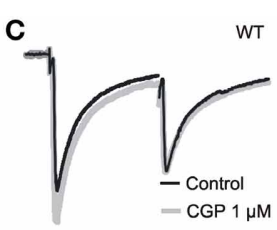
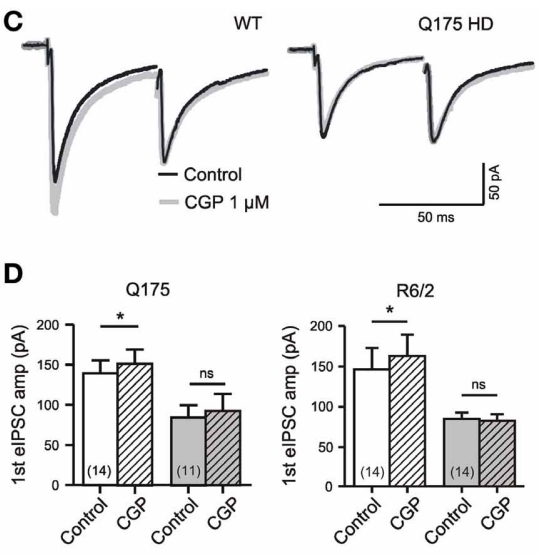

E
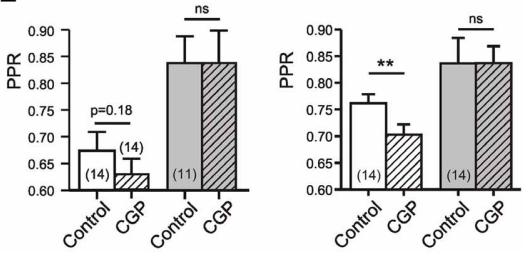

FIGURE 1 | HD-related differences in tonic GABA action in the striatum. (A) Specimen records of $I_{\text {Tonic(GABA) }}$ from SONs in slices from 1 year old WT and Q175 HD. Experiments in the presence of DNQX $(10 \mu \mathrm{M})$, APV $(50 \mu \mathrm{M})$, LY341495 (40 $\mu \mathrm{M})$; no $\mathrm{K}^{+}$channel block. Graphs on the right: Gaussian fits to all-points histograms derived from $30 \mathrm{~s}$ recording periods under control conditions and in the presence of BMI. The difference between the peaks of the fitting curves represents the amplitude of $I_{T o n i c}(G A B A)$ as plotted in (B). (B) I Tonic(GABA) obtained from WT (empty symbols) and HD mice (filled symbols).
Note similar results in the two mouse models of HD. Significance levels according to Mann-Whitney-test. (C) Sample traces to illustrate the differential effects of GABA(B) unblocking with CGP $(1 \mu \mathrm{M})$ in WT and HD. Records under similar conditions as in panel (E). (D,E) Quantification of results for elPSC amplitude and PPR. Note lack of CGP effect in HD mice and similar results from $\mathrm{Q} 175$ and R6/2 WT. Significance levels according to paired $t$-tests. The asterisks denote the following: ${ }^{*} p<0.05,{ }^{* *} p<0.01$, and $* * * p<0.001$. 
The GABA(A) receptor-mediated $\mathrm{I}_{\text {Tonic(GABA) }}$ was defined as the baseline current shift recorded during the application of $20 \mu \mathrm{M}$ of BMI (Figure 1A). The experiments were performed at a high intracellular chloride concentration without addition of potassium channel blockers and rendered similar results in WT SONs from the Q175 and the R6/2 colony (Figure 1B).

Tonic GABA(B) receptor-mediated effects were determined in a similar manner, but by bath application of the GABA antagonist CGP at a concentration of $1 \mu \mathrm{M}$. This concentration is sufficient to block saturating GABA(B) effects of GABA (Le Feuvre et al., 1997). CGP-induced changes in the paired pulse ratio (PPR), in addition to changes in the amplitude of unitary evoked IPSCs (eIPSCs), indicate a GABA(B)-dependent depression of synaptic GABA release (see Dvorzhak et al., 2013, for details). Recordings of eIPSCs from adult WT SONs (Figure 1C) illustrate that synaptic GABA release is indeed reduced by tonically active GABA(B) receptors. The typical finding after CGP administration was an increase of the first eIPSC and a decrease of the PPR (Figures 1C-E). Again, similar results were obtained in WT from the Q175 and R6/2 colonies.

Together, these results are in line with previous evidence suggesting a role of ambient GABA in the regulation of activity levels in the rodent striatum (Ade et al., 2008; Kirmse et al., 2008; Janssen et al., 2009; Santhakumar et al., 2010; Cepeda et al., 2013).

\section{HD-RELATED DIFFERENCES IN TONIC GABA ACTIONS}

Under standard recording conditions, the tonic actions of GABA were weaker in HD. Again, this applies to the GABA(A) receptormediated $\mathrm{I}_{\text {Tonic }}(\mathrm{GABA})(1 \mathrm{~A}, \mathrm{~B})$ and to the $\mathrm{GABA}(\mathrm{B})$ receptormediated presynaptic depression of synaptic GABA release (Figures 1C-E). Moreover, results obtained in Q175 were reproduced in R6/2 (Table 1).

The following experiments were aimed at clarifying the origin of the HD-related differences in tonic GABA actions.

Table 1 | Characteristics of $I_{(\text {Tonic)GABA }}$ in two mouse models of HD.

\begin{tabular}{|c|c|c|c|c|c|c|c|}
\hline & \multicolumn{3}{|c|}{ WT } & \multicolumn{3}{|c|}{ HD } & \multirow[t]{2}{*}{$p$} \\
\hline & Mean & $\pm S E$ & $N$ & Mean & $\pm S E$ & $N$ & \\
\hline \multicolumn{8}{|l|}{ Q175 SERIES 1} \\
\hline Standard & 30.7 & 2.6 & 30 & 21.9 & 2.1 & 37 & 0.0028 \\
\hline$+\operatorname{TTX} 1 \mu \mathrm{M}$ & 17.9 & 2.1 & 15 & 11.7 & 1.2 & 23 & 0.0016 \\
\hline$+\mathrm{TTX}+\mathrm{NO}-71110 \mu \mathrm{M}$ & 43.2 & 6.9 & 12 & 68.0 & 8.3 & 18 & 0.0306 \\
\hline \multicolumn{8}{|l|}{ Q175 SERIES 2} \\
\hline$+\mathrm{TTX} 1 \mu \mathrm{M}$ & 34.1 & 4.2 & 12 & 16.9 & 1.5 & 13 & 0.0003 \\
\hline+ TTX + SNAP5114 $40 \mu \mathrm{M}$ & 22.9 & 3.2 & 13 & 35.0 & 4.2 & 7 & 0.0771 \\
\hline + TTX + D-Asp $0.1 \mathrm{mM}$ & 32.7 & 5.4 & 15 & 38.0 & 4.5 & 18 & n.s. \\
\hline \multicolumn{8}{|l|}{$\mathrm{R} 6 / 2$} \\
\hline Standard & 36.1 & 5.2 & 11 & 15.7 & 3.0 & 14 & 0.0018 \\
\hline$+\operatorname{TTX} 1 \mu \mathrm{M}$ & 16.1 & 3.2 & 9 & 4.7 & 2.2 & 9 & 0.0078 \\
\hline$+\mathrm{TTX}+\mathrm{NO}-71110 \mu \mathrm{M}$ & 55.4 & 10.6 & 11 & 83.8 & 11.0 & 11 & 0.0648 \\
\hline$+\mathrm{TTX}+\mathrm{D}$-Asp $0.1 \mathrm{mM}$ & 12.4 & 1.6 & 11 & 15.9 & 3.9 & 13 & n.s. \\
\hline
\end{tabular}

The significance levels of the differences between means from WT and HD apply to Mann-Whitney tests.
First we addressed the question as to what extent action potential-(AP)-dependent synaptic GABA release contributed to the ambient GABA level that maintains $\mathrm{I}_{\text {Tonic(GABA). The results }}$ of AP block with TTX $(1 \mu \mathrm{M})$ are presented in Figures 2A,B. It can be seen that in both HD models, TTX significantly

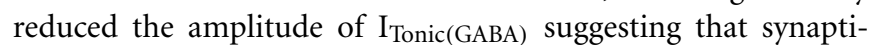
cally released GABA is a major determinant of the ambient GABA concentration. However, the differences between WT and HD SONs remained. We therefore concluded that extrasynaptic release of GABA can play a role in the regulation of ITonic(GABA).

Next we examined the effects of NO-711 $(10 \mu \mathrm{M})$, a blocker of the predominantly neuronal GABA transporter GAT-1. Block of GAT-1 was found to increase $\mathrm{I}_{\text {Tonic }}$ GABA), particularly in the HD mice, suggesting that the neuronal GABA transport operates in the uptake mode. The results also indicate that in HD mice, the tonic GABA effect is not limited by the availability of extrasynaptic receptors. Again, the results were similar in Q175 and R6/2 (Figures 2A,B, Table 1).

\section{A POSSIBLE DEPENDENCE OF ITONIC(GABA) ON THE STATE OF ASTROCYTES}

Since all results were obtained from acutely prepared brain slices, we had to address the caveat that the obtained data were influenced by the preparation procedure, recording conditions and/or the recovery dynamics after slicing. Indeed, years ago we have reported results from immature rat (Meier et al., 2003) indicating that slicing and tissue maintenance in vitro stimulates a $\mathrm{PKC}$ and Ca-dependent process of GABAergic synaptogenesis. One has to assume that the acute slice approach includes an acute response to lesion. We therefore considered the possibility that the perturbation of the tissue and the recovery dynamics after preparing the slices might differentially affect the size of $\mathrm{I}_{\text {tonic(GABA) }}$ in WT

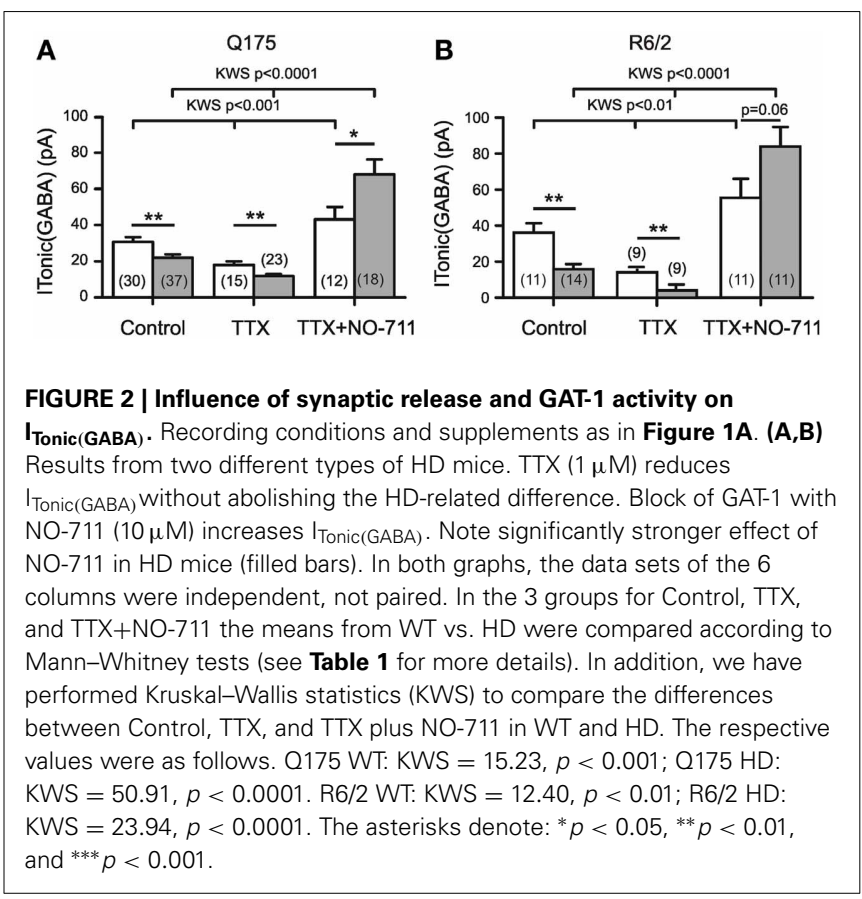


and HD mice. But what is the cellular basis of this differential reaction?

As a very first step toward answering this question we examined the time dependency of $\mathrm{I}_{\text {Tonic(GABA) }}$ in Q175 WT and HOMs (Figures 3A,B). It turned out that both in WT and HD SONs $\mathrm{I}_{\text {Tonic(GABA) }}$ was larger during the first $4 \mathrm{~h}$ after cutting the slices. Next we examined the membrane potentials $\left(\mathrm{V}_{\mathrm{m}}\right)$ of neurons (Figures 3C,D) and astrocytes (Figures 3E,F) and found relatively stable neuronal $\mathrm{V}_{\mathrm{m}}$ (albeit lower in HD), but a very pronounced time dependency of astrocytic $\mathrm{V}_{\mathrm{m}}$. Thus, high amplitudes of $\mathrm{I}_{\text {Tonic(GABA) }}$ coincided in time with astrocyte depolarization. This finding is consistent with two conclusions: (i) lesion-induced astrocyte depolarization promotes the reversal of the astrocytic GABA transporter GAT-3; (ii) in HD, an additional mechanism attenuates the non-synaptic release of GABA from astrocytes. In any case, the HD-related differences in $\mathrm{I}_{\text {Tonic(GABA) }}$ cannot be attributed to differences in the electrical driving force for astrocytic GABA release.

\section{DEPENDENCY OF TONIC GABA ACTIONS ON THE ASTROCYTIC GABA TRANSPORTER GAT-3}

To further validate the role of the astrocytic GABA transporter GAT-3 slices were for at least $7 \mathrm{~min}$ incubated in the GAT-3specific blocker SNAP5114 $(40 \mu \mathrm{M})$. All recordings were performed in Q175, within the first $4 \mathrm{~h}$ after slicing and in the presence of TTX. Figures 4A,B presents the results of the experiments with SNAP5114. Interestingly, SNAP5114 had opposite effects in WT and HD SONs. In WT, SNAP tended to reduce

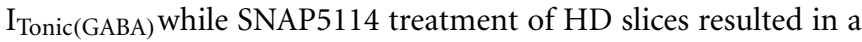
significant increase. These results support the conclusion that in WT, but not in HD mice, GAT-3 contributes to $\mathrm{I}_{\text {Tonic(GABA) }}$ and operates in the releasing mode. The weaker tonic GABA action in $\mathrm{HD}$ may then reflect the loss of GAT-3-dependent GABA release from astrocytes.

Would this hypothesis be supported in the experiments with CGP? Figures 4C-E presents the results. Indeed, SNAP5114 increased the amplitude of the 1st eIPSC and decreased the PPR,

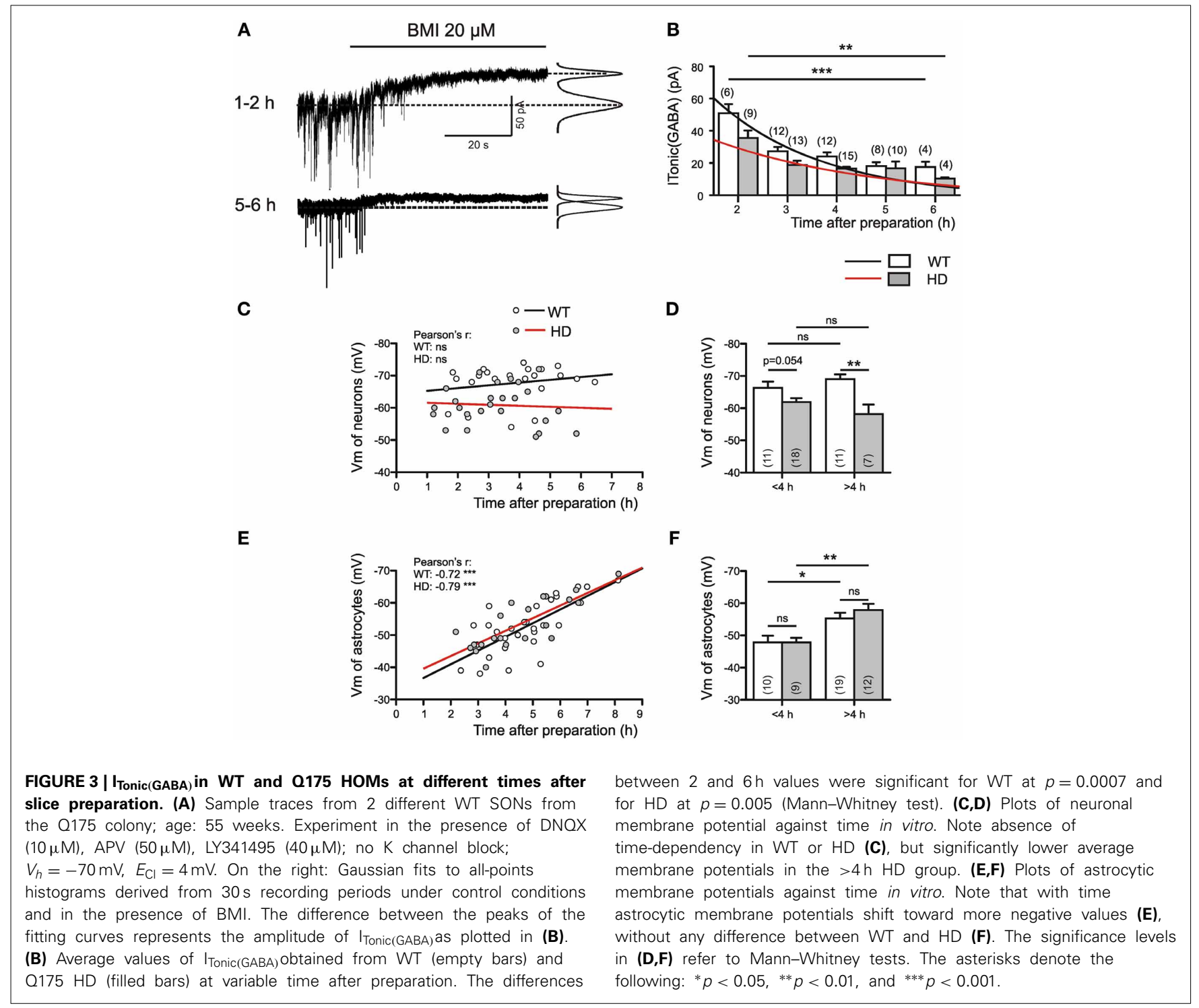




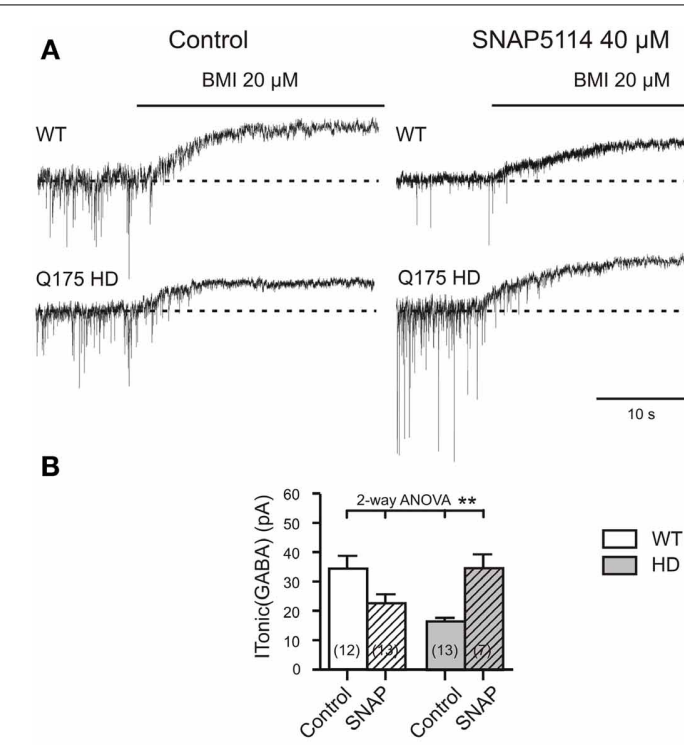

FIGURE 4 | HD-related differences in the effect of SNAP5114 on $\mathrm{I}_{\text {Tonic(GABA) }}$ and presynaptic depression of evoked GABA release. (A) Sample traces of $I_{\text {Tonic(GABA) }}$ from a Q175 WT and HD SONs. Recordings in the presence of TTX $(1 \mu \mathrm{M}), \operatorname{CGP}(1 \mu \mathrm{M})$, DNQX $(10 \mu \mathrm{M})$, APV $(50 \mu \mathrm{M})$, and LY341495 (40 $\mu$ M). Note opposite effects of GAT-3 block with SNAP5114 $(40 \mu \mathrm{M})$ in WT and HD. (B) Quantification of results from Q175 WT and HD. Significance level according to 2-Way ANOVA with subsequent Bonferroni correction for four comparisons. Normality was verified by the Kolmogorov-Smirnov test. The ANOVA table gave the following results.

\section{C}

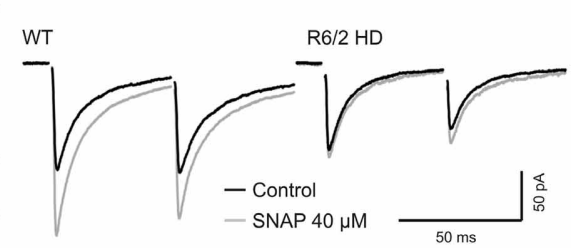

离
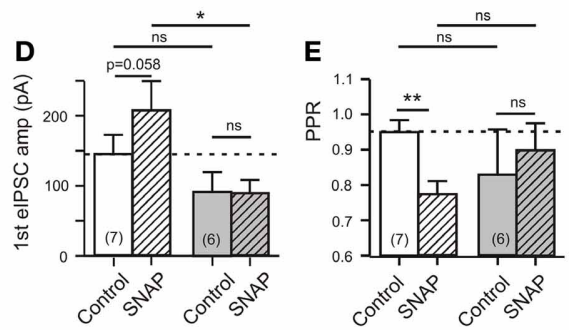

as it is to be expected when GAT-3 is blocked in the releasing mode. HD preparations lacked this effect.

\section{DEPENDENCY OF TONIC GABA ACTIONS ON GLUTAMATE TRANSPORTER ACTIVITY}

The HD-related deficiency of astrocytic GABA release under condition of strong depolarization could reflect the weakness of astrocytic glutamate uptake and the resultant change in the local sodium gradient as a cause of GAT-3 reversal. The experiments of Heja and colleagues (Heja et al., 2009, 2012) illuminated the dependency of the astrocytic GABA transporter GAT-3 on the state of glutamate transporters. In the rodent hippocampus, GAT-3 and GLT-1 (EAAT-2) are co-localized (Heja et al., 2012) and therefore exhibit a significant overlap of the respective intracellular $\left[\mathrm{Na}^{+}\right]$domains. The $\mathrm{Na}^{+}$influx associated with glutamate uptake by GLT-1 was regarded as a prerequisite for the calcium-independent GABA release by GAT-3 from astrocytes. Astrocytic depolarization and astrocytic glutamate uptake may jointly drive the non-synaptic release of GABA from astrocytes. While the former condition was present both in WT and in HD, the latter was absent in HD.

If correct, stimulation of glutamate uptake with D-aspartate might enhance non-synaptic GABA release and therefore promote tonic inhibition in HD. To test for this possibility, slices from Q175 WT mice were treated for $10 \mathrm{~min}$ with $0.1 \mathrm{mM}$ of Daspartate (Figure 5A). This had little effect in WT mice (data not shown), but in HD it produced a highly significant increase of $\mathrm{I}_{\text {Tonic(GABA) }}$ (Figure 5B). In normal mice treatment with $1 \mathrm{mM}$
Interaction: $F_{(1,41)}=14.51, p=0.0005$; Genotype: $F_{(1,41)}=0.0683$, $p=0.7951$, n.s.; Treatment with SNAP5114: $F_{(1,41)}=0.4032, p=0.5290$, n.s. (C-E) Experiments in R6/2 WT and HD. Additions: APV $50 \mu \mathrm{M}, \mathrm{DNQX}$ $20 \mu \mathrm{M}$, LY341494 $40 \mu \mathrm{M}$. (C) Records of averaged elPSCs under the indicated conditions. Note that in WT, but not HD, SNAP5114 removed a presynaptic depressant effect, as indicated by the significant decrease of the PPR (E). Significance levels according to paired $t$-tests (comparison Control vs. SNAP) and unpaired $t$-tests (comparison WT vs. HD). The asterisks denote the following: ${ }^{*} p<0.05,{ }^{* *} p<0.01$, and ${ }^{* * *} p<0.001$. of D-aspartate produced a significantly higher $\mathrm{I}_{\text {Tonic(GABA) }}$ if compared to Control (without D-asparate) or treatment with SNAP5115 (Figure 5C), thereby rendering further support to the conclusion that astrocytes indeed release GABA via GAT-3 if glutamate transporter activity is high enough.

Finally, we explored the possibility that the tonic GABA(B)mediated depression of synaptic GABA release is also influenced by glutamate transporter activity. The experiments were performed in slices from R6/2 HD mice (Figures 5D-F). In one and the same cell, synaptic transmission was sequentially tested under control condition, after $5 \mathrm{~min}$ of bath application of $\mathrm{D}$ aspartate $(1 \mathrm{mM})$ and $1 \mathrm{mM}$ of $\mathrm{D}$-aspartate supplemented with the GABA(B) receptor blocker CGP $(1 \mu \mathrm{M})$. It can be seen that $\mathrm{D}$-aspartate reduced the amplitude of eIPSCs and increased the PPR. This effect was prevented by CGP, supporting a GABA(B)dependent mechanism that is maintained by astrocytic GABA release via GLT-1/GAT-3 clusters.

The results with $\mathrm{D}$-aspartate are interesting because they show that stimulation of glutamate uptake may restore astrocytic GABA release and therefore help to repair the imbalance between extracellular glutamate and GABA levels in HD. They also suggest that in $\mathrm{HD}$, extrasynaptic $\mathrm{GABA}(\mathrm{A})$ and presynaptic $\mathrm{GABA}(\mathrm{B})$ receptors are present at sufficient densities to obtain a functional recovery within few minutes.

\section{RESCUE OF I TONIC(GABA) WITH THIP (GABOXADOL)}

Pharmacological rescue of $\mathrm{I}_{\text {Tonic(GABA) }}$ is important, but it might be advantageous to achieve its recovery without a reduction of 

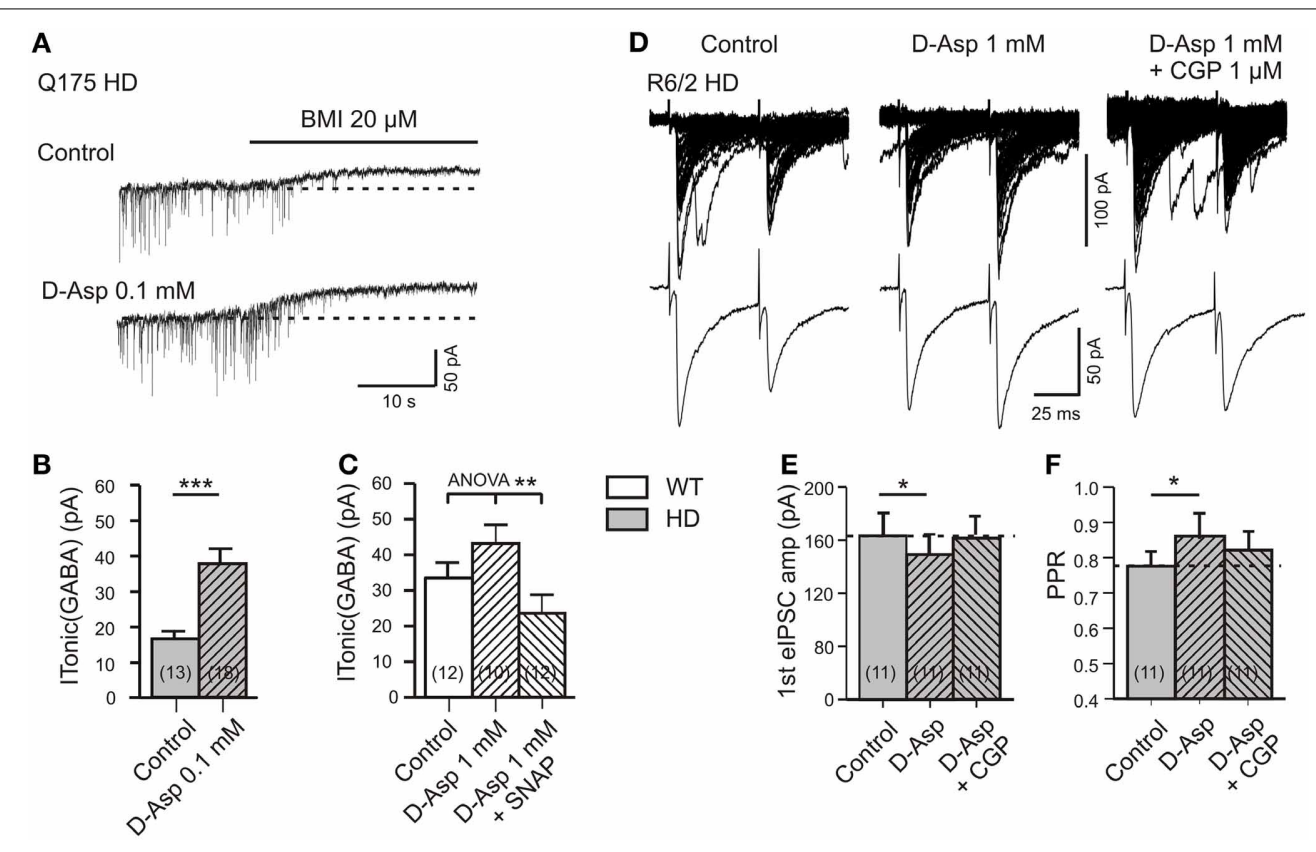

FIGURE 5 | Effects of D-aspartate on ITonic(GABA) and GABA(B) receptor-mediated presynaptic depression of synaptic GABA release. (A-C) Experiment with Q175 WT and HD. Recordings in the presence of DNQX $(10 \mu M), A P V(50 \mu M)$, and LY341494 (40 $\mu$ M). (A) Sample traces from a Q175 HD SON in the absence and presence of D-aspartate $(0.1 \mathrm{mM})$. Note the larger $I_{\text {Tonic(GABA) }}$ after 10 min treatment of HD slices with D-aspartate. (B) Quantification of the results from Q175 HD mice. Significance level according to Mann-Whitney test. (C) I Ionic(GABA) of WT SONs treated with 1 mM D-aspartate for $5 \mathrm{~min}$. Note the highly significant decrease in the presence of SNAP5115 $(40 \mu M)$. Significance level according to One-Way ANOVA with post-hoc Bonferroni correction $\left[F_{(2,31)}=6.603, p=0.0041\right]$. The data sets represented

in the three columns are independent, not matched. (D-F) elPSCs in R6/2 WT and HD SONs in the presence of APV $(50 \mu \mathrm{M})$, DNQX $(20 \mu \mathrm{M})$, and LY341494 $(40 \mu \mathrm{M})$. (D) Records of averaged eIPSCs from one and the same HD SON under the indicated conditions. Note the rescue of tonic GABA(B)-mediated depression of synaptic GABA release in HD after treatment of $1 \mathrm{mMD}$-aspartate for $5 \mathrm{~min}$. (E,F) Quantification of the results from HD SONs tested for changes in elPSC amplitude (E) and PPR (F) in the presence of D-aspartate and D-aspartate plus CGP. The indicated differences between Control and D-aspartate reflect the amount of tonic presynaptic depression of synaptic GABA release according to Wilcoxon's matched-pairs signed rank test after Bonferroni correction for multiple comparison. ${ }^{*} p<0.05,{ }^{* *} p<0.01$, and ${ }^{* * *} p<0.001$. synaptic GABA release. We therefore examined the effects of the delta-subunit-specific GABA(A) receptor hyperagonist THIP (Figures 6A,B). The latter was applied at least $5 \mathrm{~min}$ prior to addition of BMI. The records were performed in the presence of TTX, DNQX, APV, and LY341495. It was found that in HD about $0.33 \mu \mathrm{M}$ of THIP were sufficient to restore $\mathrm{I}_{\text {Tonic(GABA) }}$ to the WT level (Figure 6C). As it cannot be excluded that THIP at higher concentrations activated both extrasynaptic and synaptic $\mathrm{GABA}(\mathrm{A})$ receptors, we estimated the average amplitudes of miniature IPSCs expecting an IPSC decrease if part of the receptors were occupied by THIP. However, no significant difference was found between the IPSC amplitudes recorded in the absence of THIP and THIP at a concentration of $0.33 \mu \mathrm{M}$. Thus, application of THIP might be another means to rescue tonic inhibition in the striatum afflicted by HD.

\section{DISCUSSION}

Our experiments demonstrate that symptomatic HD is associated with a weakness of tonic GABA action and illuminate a so far neglected pathophysiological element of $\mathrm{HD}$ in astrocytes, the incapacity of GAT-3 to release GABA under condition of astrocyte depolarization. The weakness of non-synaptic GABA release from astrocytes in $\mathrm{HD}$ was not only reflected by the lower amplitudes of $\mathrm{I}_{\text {Tonic(GABA) }}$ but also by the reduced strength of GABA(B)-mediated presynaptic depression of synaptic GABA release. Interestingly, treatment of slices with an exogenous substrate of glutamate transport rescued non-synaptic GABA release supporting the hypothesis that GAT-3 activity is coupled to astrocytic glutamate transport (Heja et al., 2009, 2012).

\section{REDUCED EXTRACELLULAR GABA CONCENTRATION IN HD?}

Several attempts have been made to determine transmitter concentrations in postmortem normal and HD brains and by dialysis and HPLC of animal preparations. A pioneer study by Spokes et al. (1979) reported an unchanged GABA concentration in the postmortem HD striatum despite a significant decrease in the activity of glutamate decarboxylase. Later studies described a massive decrease of $[\mathrm{GABA}]_{\mathrm{ec}}$ in the striatum (Ellison et al., 1987) and globus pallidus of choreic patients (Kanazawa et al., 1985) and in mice treated with quinolinic acid, an earlier model of HD (Ellison et al., 1987). However, to measure ambient transmitter concentrations under resting conditions and independently of synaptic GABA release, it might be better to take advantage of endogenous high affinity receptors (Le Feuvre et al., 1997; Dvorzhak et al., 2010), unless the transmitter receptors themselves set limits to the detection of extracellular transmitters. This was not the case here, since in HD slices with GAT-1 block or treatment with D-aspartate $\mathrm{I}_{\text {Tonic(GABA) }}$ 


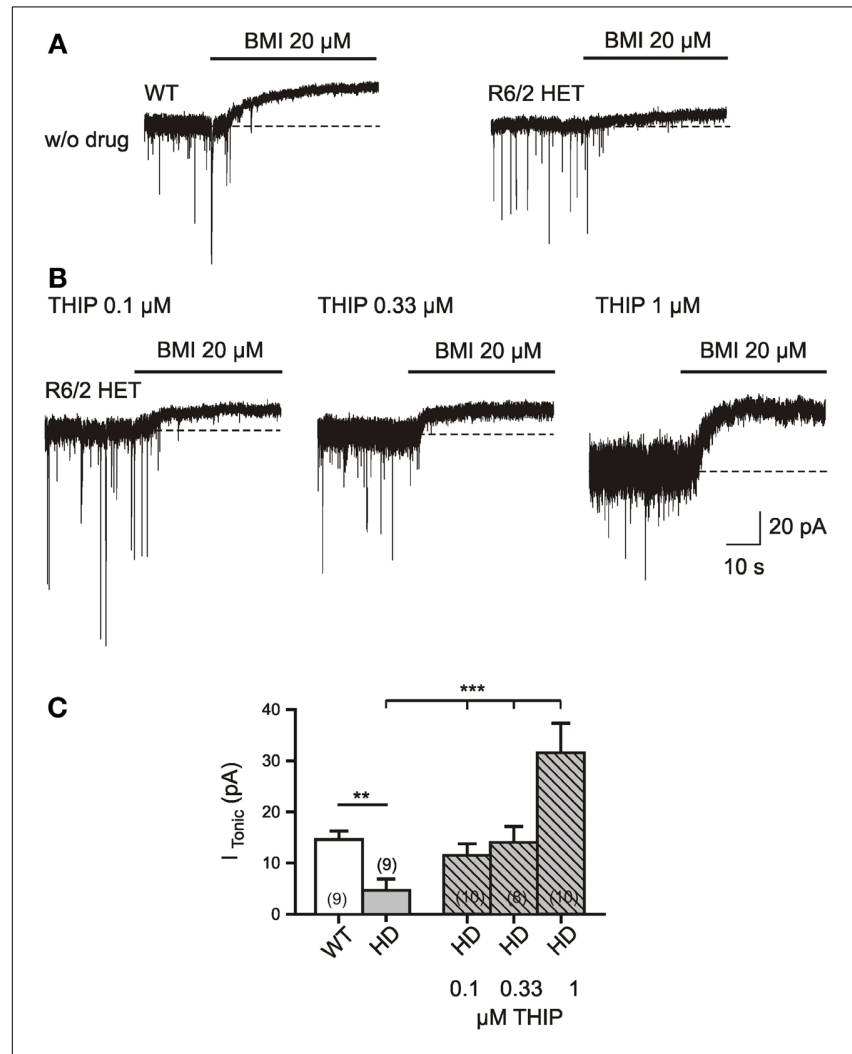

FIGURE 6 | Rescue of $\mathrm{I}_{\text {Tonic (GABA) }}$ in R6/2 $\mathrm{HD}$ mice by bath application of THIP (gaboxadol) at a concentration of $0.33 \mu \mathbf{M}$. (A,B) Specimen records in the absence (A) and presence (B) of delta subunit specific GABA(A) receptor hyper-agonist THIP $(0.1 \mu \mathrm{M}, 0.33 \mu \mathrm{M}$, and $1 \mu \mathrm{M})$. The recording conditions were similar to those in Figure 1. Experiments were performed in the presence of TTX $(1 \mu \mathrm{M})$, DNQX $(10 \mu \mathrm{M})$, APV $(50 \mu \mathrm{M})$, LY341495 (40 $\mu \mathrm{M})$; no $\mathrm{K}$ channel block; $V_{h}=-70 \mathrm{mV}, E_{\mathrm{Cl}}=4 \mathrm{mV}$. THIP was applied through a slow drug delivery system to the bath solution (exchange time ca. $1 \mathrm{~min}$ ). (C) Quantification of the results. The asterisks denote the following: ${ }^{*} p<0.05,{ }^{* *} p<0.01$, and ${ }^{* * *} p<0.001$. The comparison between WT and HD was performed by the Mann-Whitney test. The THIP effect on HD SONs was tested by One-Way ANOVA (multiple comparison against the "THIPO" group) and resulted in $F_{(3,33)}=9.731, p<0.0001$ for the THIP concentrations $0,0.1,0.33$, and $1 \mu \mathrm{M}$.

amplitudes were even higher than in the respective WT controls.

Nonetheless, it would be premature to exclude the possibility that cell-type-specific differences/changes in the expression of transmitter receptors add to the presently observed HD-related differences. It is known that in the adult brain, $\mathrm{I}_{\text {Tonic(GABA) }}$ primarily depends on GABA(A) receptors containing a delta subunit (Stell et al., 2003). The latter is likely to be more abundant in D1-expressing SONs (Santhakumar et al., 2010). Indeed, in the absence of TTX, HD-related differences might be more prominent in D2 SONs (Cepeda et al., 2013).

\section{ASTROCYTIC GABA RELEASE?}

In the rodent striatum $95 \%$ of the neurons express a GABAergic phenotype, and interneurons together with other SONs establish an extensive coverage with GABAergic synapses (Wilson, 2007;
Tepper et al., 2008). Striatal slices of WT and HD origin exhibit AP-dependent spontaneous activity (Dvorzhak et al., 2013). It is therefore not surprising that a major part of $\mathrm{I}_{\text {Tonic(GABA) }}$ depended on AP-mediated synaptic release of GABA. The present experiments showed, however that in both HD models the difference between WT and HD persisted after exclusion of APdependent synaptic GABA release with TTX.

GABA of non-synaptic origin might be provided through the GABA transporters GAT-1 and GAT-3 [see Jin et al. (2011a) for a recent comprehensive review on data from basal ganglia]. However, previous results from the normal rodent striatum suggested an increase of $[\mathrm{GABA}]_{\mathrm{ec}}$ after pharmacological block of GAT-1 (Waldmeier et al., 1992; Kirmse et al., 2008). This result is now confirmed and extended by showing that the NO-711induced increase of GABA uptake was even larger in HD.

The remaining possibility is that GABA is provided by astrocytes. The concept of gliotransmitter release in a voltage- and/or calcium-dependent manner has already received broad support. It is known that astrocytes release amino acids (glutamate, D-serine), nucleotides (adenosine) and neuropeptides (brainderived neurotrophic factor, natriuretic peptide) and thereby modify the activity of neighboring neurons and their synaptic signals (Parpura and Zorec, 2010). GABA is seldom on the list of gliotransmitters (but see Glykys and Mody, 2007b; Angulo et al., 2008), possibly because astrocytes lack the respective enzymes glutamate decarboxylase, GAD65 and GAD67. However, there is a GAD-independent form of GABA synthesis from putrescine (Seiler et al., 1979; Angulo et al., 2008; Heja et al., 2012). In addition, GABA could also be shuttled from sites of GABA uptake to sites of GABA release, similar to the spatial potassium buffering of glial cells (Lux et al., 1986; Reichenbach, 1991). GABA immunolabel was found in GFAP-positive hippocampal astrocytes (Le Meur et al., 2012).

Previous studies on the role of glial GABA transporters in the rodent brain have yielded somewhat controversial results. Keros and Hablitz (2005) examined the function of GAT-3 and GAT- 1 in the juvenile rat cerebral cortex and found that GAT- 3 contributes little to the regulation of inhibition unless GAT-1 is blocked with NO-711. In this case, GAT-3 and GAT-1 were thought to operate synergistically in the uptake mode with the prediction that the presence of SNAP-5114 should enhance $\mathrm{I}_{\text {Tonic(GABA) }}$ as well as GABA(B)-mediated presynaptic depression of evoked IPSCs. Results supporting this notion were obtained in a previous study from our own lab based on recordings from striatal output neurons (SONs) in juvenile normal mice (Kirmse et al., 2009).

Support for a GAT-3-dependent enhancement of inhibition under normal conditions was derived from another study of the rodent cerebral cortex, where recordings were made in layer $\mathrm{V}$ pyramidal neurons (Kinney, 2005). In this case, SNAP-5114 was found to increase the amplitude of eIPSCs suggesting a decrease of GABA(B) receptor-mediated depression of synaptic GABA release when GAT-3 is not active. In recordings from globus pallidus neurons, SNAP-5114 was also found to increase eIPSC amplitudes (Jin et al., 2011b).

A recent study on the role of GAT-3 in the hippocampus was performed in freely moving rats using microdialysis with subsequent HPLC measurement of GABA concentration in the 
acquired probes (Kersante et al., 2013). This study showed a contribution of GAT-3 to GABA uptake when GAT-1 was blocked. No evidence was found for astrocytic GABA release.

As the state of astrocytes in a given slice preparation can have a major impact on the strength of glutamate uptake, on one side, and ambient GABA concentrations, on the other side, it may become necessary to provide some functional checkpoints from astrocytes to compare the results obtained on tonic GABA actions under specific experimental settings.

\section{RESCUE OF FUNCTION IN HD}

It is known for more than a decade that astrocytes are affected by HD (Vonsattel and DiFiglia, 1998; Faideau et al., 2010). The so far most prominent functional deficit ascribed to astrocytes is the deficiency of glutamate uptake (Lievens et al., 2001; Behrens et al., 2002; Petr et al., 2013) and the resultant elevation of extracellular glutamate concentration in the striatum (Arzberger et al., 1997; Lee et al., 2013).

The present experiments add a new facet to the pathophysiology of HD by demonstrating an HD-related switch in the polarity of GAT-3 action. Our results predict that block of the non-physiological GABA uptake in HD would, within few minutes, restore the characteristics of tonic GABA actions to WT level. SNAP5114 is a nipecotic acid derivative with "moderate affinity and selectivity for the cloned human GAT-3" (Dhar et al., 1994). It has an $\mathrm{IC}_{50}$ of about $5 \mu \mathrm{M}$ for GAT-3, $20 \mu \mathrm{M}$ for GAT-2, $140 \mu \mathrm{M}$ for BGT-1, and $400 \mu \mathrm{M}$ for GAT-1. Should more effective and selective blockers of GAT-3 become available, it might become worthwhile to examine the capacity of GAT-3 to alleviate motor symptoms of HD.

At present, the easiest way to restore $\mathrm{I}_{\text {Tonic(GABA) }}$ seems to be the application of gaboxadol (THIP). This compound is an already well-characterized delta-subunit-specific GABA(A) hyperagonist and has for some time been considered for treatment of insomnia (Wafford and Ebert, 2006). In view of the presently discovered HD-related deficit in $\mathrm{I}_{\text {Tonic(GABA), the ques- }}$ tion arises whether HD patients can benefit from this drug. Unfortunately, in a short ( 2 weeks) clinical trial on four patients with choreatic and one patient with hypokinetic-rigid type of $\mathrm{HD}$, gaboxadol failed to provide the expected benefits but merely caused sleepiness and unsteadiness of gait (Foster et al., 1983).

Finally, our results with D-aspartate underscore the need to stimulate/recover the function of glutamate transport. A promising agent along this line is the antibiotic ceftriaxone (Sari et al., 2010). Further experiments will show to what extent this drug can restore tonic GABA actions in case of symptomatic HD.

\section{ACKNOWLEDGMENTS}

This work was supported by the CHDI foundation (A-4480), German Research Council DFG (Gr986/10-1, Exc 257/1) and Charité Research Funds.

\section{REFERENCES}

Ade, K. K., Janssen, M. J., Ortinski, P. I., and Vicini, S. (2008). Differential tonic GABA conductances in striatal medium spiny neurons. J. Neurosci. 28, 1185-1197. doi: 10.1523/JNEUROSCI.3908-07.2008

Angulo, M. C., Le Meur, K., Kozlov, A. S., Charpak, S., and Audinat, E. (2008). GABA, a forgotten gliotransmitter. Prog. Neurobiol. 86, 297-303. doi: 10.1016/j.pneurobio.2008.08.002
Arzberger, T., Krampfl, K., Leimgruber, S., and Weindl, A. (1997). Changes of NMDA receptor subunit (NR1, NR2B) and glutamate transporter (GLT1) mRNA expression in Huntington's disease-an in situ hybridization study. $J$. Neuropathol. Exp. Neurol. 56, 440-454. doi: 10.1097/00005072-19970400000013

Behrens, P. F., Franz, P., Woodman, B., Lindenberg, K. S., and Landwehrmeyer, G. B. (2002). Impaired glutamate transport and glutamate-glutamine cycling: downstream effects of the Huntington mutation. Brain 125, 1908-1922. doi: 10.1093/brain/awf180

Borden, L. A. (1996). GABA transporter heterogeneity: pharmacology and cellular localization. Neurochem. Int. 29, 335-356. doi: 10.1016/0197-0186(95)00158-1

Brickley, S. G., and Mody, I. (2012). Extrasynaptic GABA(A) receptors: their function in the CNS and implications for disease. Neuron 73, 23-34. doi: 10.1016/j.neuron.2011.12.012

Cepeda, C., Galvan, L., Holley, S. M., Rao, S. P., Andre, V. M., Botelho, E. P., et al. (2013). Multiple sources of striatal inhibition are differentially affected in Huntington's disease mouse models. J. Neurosci. 33, 7393-7406. doi: 10.1523/JNEUROSCI.2137-12.2013

Connelly, W. M., Fyson, S. J., Errington, A. C., McCafferty, C. P., Cope, D. W., Di Giovanni, G., et al. (2013). GABAB receptors regulate extrasynaptic GABAA receptors. J. Neurosci. 33, 3780-3785. doi: 10.1523/JNEUROSCI.4989-12.2013

Dalby, N. O. (2003). Inhibition of gamma-aminobutyric acid uptake: anatomy, physiology and effects against epileptic seizures. Eur. J. Pharmacol. 479, 127-137. doi: 10.1016/j.ejphar.2003.08.063

Dhar, T. G., Borden, L. A., Tyagarajan, S., Smith, K. E., Branchek, T. A., Weinshank, R. L., et al. (1994). Design, synthesis and evaluation of substituted triarylnipecotic acid derivatives as GABA uptake inhibitors: identification of a ligand with moderate affinity and selectivity for the cloned human GABA transporter GAT-3. J. Med. Chem. 37, 2334-2342. doi: 10.1021/jm00041a012

Dvorzhak, A., Myakhar, O., Unichenko, P., Kirmse, K., and Kirischuk, S. (2010). Estimation of ambient GABA levels in layer I of the mouse neonatal cortex in brain slices. J. Physiol. 588, 2351-2360. doi: 10.1113/jphysiol.2010.187054

Dvorzhak, A., Semtner, M., Faber, D. S., and Grantyn, R. (2013). Tonic mGluR5/CB1-dependent suppression of inhibition as a pathophysiological hallmark in the striatum of mice carrying a mutant form of huntingtin. J. Physiol. 591, 1145-1166. doi: 10.1113/jphysiol.2012.241018

Ellison, D. W., Beal, M. F., Mazurek, M. F., Malloy, J. R., Bird, E. D., and Martin, J. B. (1987). Amino acid neurotransmitter abnormalities in Huntington's disease and the quinolinic acid animal model of Huntington's disease. Brain 110, 1657-1673. doi: 10.1093/brain/110.6.1657

Faideau, M., Kim, J., Cormier, K., Gilmore, R., Welch, M., Auregan, G., et al. (2010). In vivo expression of polyglutamine-expanded huntingtin by mouse striatal astrocytes impairs glutamate transport: a correlation with Huntington's disease subjects. Hum. Mol. Genet. 19, 3053-3067. doi: 10.1093/hmg/ddq212

Farrant, M., and Nusser, Z. (2005). Variations on an inhibitory theme: phasic and tonic activation of GABA(A) receptors. Nat. Rev. Neurosci. 6, 215-229. doi: $10.1038 / \mathrm{nrn} 1625$

Foster, N. L., Chase, T. N., Denaro, A., Hare, T. A., and Tamminga, C. A. (1983). THIP treatment of Huntington's disease. Neurology. 33, 637-639. doi: 10.1212/WNL.33.5.637

Glykys, J., and Mody, I. (2007a). Activation of GABAA receptors: views from outside the synaptic cleft. Neuron 56, 763-770. doi: 10.1016/j.neuron.2007.11.002

Glykys, J., and Mody, I. (2007b). The main source of ambient GABA responsible for tonic inhibition in the mouse hippocampus. J. Physiol. 582, 1163-1178. doi: 10.1113/jphysiol.2007.134460

Ha, A. D., and Fung, V. S. (2012). Huntington's disease. Curr. Opin. Neurol. 25, 491-498. doi: 10.1097/WCO.0b013e3283550c97

Heja, L., Barabas, P., Nyitrai, G., Kekesi, K. A., Lasztoczi, B., Toke, O., et al. (2009). Glutamate uptake triggers transporter-mediated GABA release from astrocytes. PLoS. ONE. 4:e7153. doi: 10.1371/journal.pone.0007153

Heja, L., Nyitrai, G., Kekesi, O., Dobolyi, A., Szabo, P., Fiath, R., et al. (2012). Astrocytes convert network excitation to tonic inhibition of neurons. BMC.Biol. 10:26. doi: 10.1186/1741-7007-10-26

Janssen, M. J., Ade, K. K., Fu, Z., and Vicini, S. (2009). Dopamine modulation of GABA tonic conductance in striatal output neurons. J. Neurosci. 29, 5116-5126. doi: 10.1523/JNEUROSCI.4737-08.2009

Jin, X. T., Galvan, A., Wichmann, T., and Smith, Y. (2011a). Localization and function of GABA transporters GAT-1 and GAT-3 in the basal ganglia. Front. Syst. Neurosci. 5:63. doi: 10.3389/fnsys.2011.00063 
Jin, X. T., Pare, J. F., and Smith, Y. (2011b). Differential localization and function of GABA transporters, GAT-1 and GAT-3, in the rat globus pallidus. Eur. J. Neurosci. 33, 1504-1518. doi: 10.1111/j.1460-9568.2011.07636.x

Kanazawa, I., Sasaki, H., Muramoto, O., Matsushita, M., Mizutani, T., Iwabuchi, K., et al. (1985). Studies on neurotransmitter markers and striatal neuronal cell density in Huntington's disease and dentatorubropallidoluysian atrophy. J. Neurol. Sci. 70, 151-165. doi: 10.1016/0022-510X(85)90084-X

Keros, S., and Hablitz, J. J. (2005). Subtype-specific GABA transporter antagonists synergistically modulate phasic and tonic GABAA conductances in rat neocortex. J. Neurophysiol. 94, 2073-2085. doi: 10.1152/jn.00520.2005

Kersante, F., Rowley, S. C., Pavlov, I., Gutierrez-Mecinas, M., Semyanov, A., Reul, J. M., et al. (2013). A functional role for both -aminobutyric acid (GABA) transporter-1 and GABA transporter-3 in the modulation of extracellular GABA and GABAergic tonic conductances in the rat hippocampus. J. Physiol. 591, 2429-2441. doi: 10.1113/jphysiol.2012.246298

Kinney, G. A. (2005). GAT-3 transporters regulate inhibition in the neocortex. $J$. Neurophysiol. 94, 4533-4537. doi: 10.1152/jn.00420.2005

Kirmse, K., and Kirischuk, S. (2006). Ambient GABA constrains the strength of GABAergic synapses at Cajal-Retzius cells in the developing visual cortex. $J$. Neurosci. 26, 4216-4227. doi: 10.1523/JNEUROSCI.0589-06.2006

Kirmse, K., Kirischuk, S., and Grantyn, R. (2008). Activity of the GABA transporter 1 regulates GABAergic synaptic transmission in striatal projection neurons. $J$. Physiol. 586, 5665-5678. doi: 10.1113/jphysiol.2008.161943

Kirmse, K., Kirischuk, S., and Grantyn, R. (2009). Role of GABA Transporter 3 in GABAergic synaptic transmission at striatal output neurons. Synapse 63, 921-929. doi: 10.1002/syn.20675

Laviv, T., Riven, I., Dolev, I., Vertkin, I., Balana, B., Slesinger, P. A., et al. (2010). Basal GABA regulates GABA(B)R conformation and release probability at single hippocampal synapses. Neuron 67, 253-267. doi: 10.1016/j.neuron.2010. 06.022

Lee, W., Reyes, R. C., Gottipati, M. K., Lewis, K., Lesort, M., Parpura, V., et al. (2013). Enhanced Ca-dependent glutamate release from astrocytes of the BACHD Huntington's disease mouse model. Neurobiol. Dis. 58, 192-199. doi: 10.1016/j.nbd.2013.06.002

Le Feuvre, Y., Fricker, D., and Leresche, N. (1997). GABAA receptor-mediated IPSCs in rat thalamic sensory nuclei: patterns of discharge and tonic modulation by GABAB autoreceptors. J. Physiol. 502, 91-104. doi: 10.1111/j.14697793.1997.091bl.x

Le Meur, K., Mendizabal-Zubiaga, J., Grandes, P., and Audinat, E. (2012). GABA release by hippocampal astrocytes. Front. Comput. Neurosci. 6:59. doi: 10.3389/fncom.2012.00059

Lievens, J. C., Woodman, B., Mahal, A., Spasic-Boscovic, O., Samuel, D., KerkerianLe Goff, L., et al. (2001). Impaired glutamate uptake in the R6 Huntington's disease transgenic mice. Neurobiol. Dis. 8, 807-821. doi: 10.1006/nbdi.2001.0430

Lux, H. D., Heinemann, U., and Dietzel, I. (1986). Ionic changes and alterations in the size of the extracellular space during epileptic activity. Adv. Neurol. 44, 619-639.

Mangiarini, L., Sathasivam, K., Seller, M., Cozens, B., Harper, A., Hetherington, C., et al. (1996). Exon 1 of the HD gene with an expanded CAG repeat is sufficient to cause a progressive neurological phenotype in transgenic mice. Cell 87, 493-506. doi: 10.1016/S0092-8674(00)81369-0

Mapelli, L., Rossi, P., Nieus, T., and D'Angelo, E. (2009). Tonic activation of GABAB receptors reduces release probability at inhibitory connections in the cerebellar glomerulus. J. Neurophysiol. 101, 3089-3099. doi: 10.1152/jn.91190.2008

Meier, J., Akyeli, J., Kirischuk, S., and Grantyn, R. (2003). GABA(A) receptor activity and PKC control inhibitory synaptogenesis in CNS tissue slices. Mol. Cell. Neurosci. 23, 600-613. doi: 10.1016/S1044-7431(03)00079-4

Menalled, L. B., Sison, J. D., Dragatsis, I., Zeitlin, S., and Chesselet, M. F. (2003). Time course of early motor and neuropathological anomalies in a knock-in mouse model of Huntington's disease with 140 CAG repeats. J. Comp. Neurol. 465, 11-26. doi: 10.1002/cne.10776

Miller, B. R., Dorner, J. L., Shou, M., Sari, Y., Barton, S. J., Sengelaub, D. R., et al. (2008). Up-regulation of GLT1 expression increases glutamate uptake and attenuates the Huntington's disease phenotype in the R6/2 mouse. Neuroscience. 153, 329-337. doi: 10.1016/j.neuroscience.2008.02.004

Miller, B. R., Walker, A. G., Barton, S. J., and Rebec, G. V. (2011). Dysregulated neuronal activity patterns implicate corticostriatal circuit dysfunction in multiple rodent models of Huntington's disease. Front. Syst. Neurosci. 5:26. doi: $10.3389 /$ fnsys.2011.00026
Minelli, A., DeBiasi, S., Brecha, N. C., Zuccarello, L. V., and Conti, F. (1996). GAT-3, a high-affinity GABA plasma membrane transporter, is localized to astrocytic processes, and it is not confined to the vicinity of GABAergic synapses in the cerebral cortex. J. Neurosci. 16, 6255-6264.

Mody, I. (2005). Aspects of the homeostaic plasticity of GABAA receptor-mediated inhibition. J. Physiol. 562, 37-46. doi: 10.1113/jphysiol.2004.077362

Nimmerjahn, A., Kirchhoff, F., Kerr, J. N., and Helmchen F. (2004). Sulforhodamine 101 as a specific marker of astroglia in the neocortex in vivo. Nat. Methods. 1, 31-37. doi: 10.1038/nmeth706

Parpura, V., and Zorec, R. (2010). Gliotransmission: exocytotic release from astrocytes. Brain Res. Rev. 63, 83-92. doi: 10.1016/j.brainresrev.2009.11.008

Petr, G. T., Schultheis, L. A., Hussey, K. C., Sun, Y., Dubinsky, J. M., Aoki, C., et al. (2013). Decreased expression of GLT-1 in the R6/2 model of Huntington's disease does not worsen disease progression. Eur. J. Neurosci. 38, 2477-2490. doi: 10.1111/ejn.12202

Radian, R., Ottersen, O. P., Storm-Mathisen, J., Castel, M., and Kanner, B. I. (1990). Immunocytochemical localization of the GABA transporter in rat brain. $J$. Neurosci. 10, 1319-1330.

Ransom, C. B., Tao, W., Wu, Y., Spain, W. J., and Richerson, G. B. (2013). Rapid regulation of tonic GABA currents in cultured rat hippocampal neurons. $J$. Neurophysiol. 109, 803-812. doi: 10.1152/jn.00460.2012

Ransom, C. B., Wu, Y., and Richerson, G. B. (2010). Postdepolarization potentiation of GABAA receptors: a novel mechanism regulating tonic conductance in hippocampal neurons. J. Neurosci. 30, 7672-7684. doi: 10.1523/JNEUROSCI.0290-10.2010

Reichenbach, A. (1991). Glial K+ permeability and CNS K+ clearance by diffusion and spatial buffering. Ann. N.Y. Acad. Sci. 633, 272-286. doi: 10.1111/j.17496632.1991.tb15620.x

Ribak, C. E., Tong, W. M. Y., and Brecha, N. C. (1996). GABA plasma membrane transporters, GAT-1 and GAT-3, display different distributions in the rat hippocampus. J. Comp. Neurol. 367, 595-606. doi: 10.1002/(SICI)10969861(19960415)367:4<595::AID-CNE9>3.0.CO;2-\#

Richerson, G. B., and Wu, Y. (2003). Dynamic equilibrium of neurotransmitter transporters: not just for reuptake anymore. J. Neurophysiol. 90, 1363-1374. doi: 10.1152/jn.00317.2003

Ross, C. A., and Tabrizi, S. J. (2011). Huntington's disease: from molecular pathogenesis to clinical treatment. Lancet Neurol. 10, 83-98. doi: 10.1016/S14744422(10)70245-3

Santhakumar, V., Jones, R. T., and Mody, I. (2010). Developmental regulation and neuroprotective effects of striatal tonic GABAA currents. Neuroscience. 167, 644-655. doi: 10.1016/j.neuroscience.2010.02.048

Sari, Y., Prieto, A. L., Barton, S. J., Miller, B. R., and Rebec, G. V. (2010). Ceftriaxone-induced up-regulation of cortical and striatal GLT1 in the R6/2 model of Huntington's disease. J. Biomed. Sci. 17, 62-17. doi: 10.1186/14230127-17-62

Scimemi, A., Semyanov, A., Sperk, G., Kullmann, D. M., and Walker, M. C. (2005). Multiple and plastic receptors mediate tonic GABAA receptor currents in the hippocampus. J. Neurosci. 25, 10016-10024. doi: 10.1523/JNEUROSCI.252005.2005

Seiler, N., Schmidt-Glenewinkel, T., and Sarhan, S. (1979). On the formation of gamma-aminobutyric acid from putrescine in brain. J. Biochem. 86, 277-278.

Semyanov, A., Walker, M. C., and Kullmann, D. M. (2003). GABA uptake regulates cortical excitability via cell type-specific tonic inhibition. Nat. Neurosci. 6, 484-490. doi: 10.1038/nn1043

Semyanov, A., Walker, M. C., Kullmann, D. M., and Silver, R. A. (2004). Tonically active GABA A receptors: modulating gain and maintaining the tone. Trends Neurosci. 27, 262-269. doi: 10.1016/j.tins.2004.03.005

Song, I., Savtchenko, L., and Semyanov, A. (2011). Tonic excitation or inhibition is set by GABA(A) conductance in hippocampal interneurons. Nat. Commun. 2, 376. doi: $10.1038 /$ ncomms 1377

Spokes, E. G., Garrett, N. J., and Iversen, L. L. (1979). Differential effects of agonal status on measurements of GABA and glutamate decarboxylase in human post-mortem brain tissue from control and Huntington's chorea subjects. $J$. Neurochem. 33, 773-778. doi: 10.1111/j.1471-4159.1979.tb05223.x

Stell, B. M., Brickley, S. G., Tang, C. Y., Farrant, M., and Mody, I. (2003). Neuroactive steroids reduce neuronal excitability by selectively enhancing tonic inhibition mediated by delta subunit-containing GABAA receptors. Proc. Natl. Acad. Sci. U.S.A. 100, 14439-14444. doi: 10.1073/pnas.2435457100 
Tepper, J. M., Wilson, C. J., and Koos, T. (2008). Feedforward and feedback inhibition in neostriatal GABAergic spiny neurons. Brain Res. Rev. 58, 272-281. doi: 10.1016/j.brainresrev.2007.10.008

Vonsattel, J. P., and DiFiglia, M. (1998). Huntington disease. J. Neuropathol. Exp. Neurol. 57, 369-384. doi: 10.1097/00005072-199805000-00001

Wafford, K. A., and Ebert, B. (2006). Gaboxadol-a new awakening in sleep. Curr. Opin. Pharmacol. 6, 30-36. doi: 10.1016/j.coph.2005.10.004

Waldmeier, P. C., Stocklin, K., and Feldtrauer, J. J. (1992). Weak effects of local and systemic administration of the GABA uptake inhibitor, SKandF 89976, on extracellular GABA in the rat striatum. Naunyn Schmiedebergs Arch.Pharmacol. 345, 544-547. doi: 10.1007/BF00168946

Wilson, C. J. (2007). GABAergic inhibition in the neostriatum. Prog. Brain Res. 160, 91-110. doi: 10.1016/S0079-6123(06)60006-X

Wu, Y., Wang, W., Diez-Sampedro, A., and Richerson, G. B. (2007). Nonvesicular inhibitory neurotransmission via reversal of the GABA transporter GAT-1. Neuron 56, 851-865. doi: 10.1016/j.neuron.2007.10.021

Yoon, B. E., Woo, J., and Lee, C. J. (2012). Astrocytes as GABA-ergic and GABAceptive cells. Neurochem. Res. 37, 2474-2479. doi: 10.1007/s11064-012-0808-Z
Conflict of Interest Statement: The authors declare that the research was conducted in the absence of any commercial or financial relationships that could be construed as a potential conflict of interest.

Received: 09 August 2013; accepted: 04 November 2013; published online: 26 November 2013.

Citation: Wójtowicz AM, Dvorzhak A, Semtner M and Grantyn R (2013) Reduced tonic inhibition in striatal output neurons from Huntington mice due to loss of astrocytic GABA release through GAT-3. Front. Neural Circuits 7:188. doi: 10.3389/fncir. 2013.00188

This article was submitted to the journal Frontiers in Neural Circuits.

Copyright (c) 2013 Wójtowicz, Dvorzhak, Semtner and Grantyn. This is an openaccess article distributed under the terms of the Creative Commons Attribution License (CC BY). The use, distribution or reproduction in other forums is permitted, provided the original author(s) or licensor are credited and that the original publication in this journal is cited, in accordance with accepted academic practice. No use, distribution or reproduction is permitted which does not comply with these terms. 